\title{
Sealing Ability of Mineral Trioxide Aggregate, Biodentine and Glass Ionomer as Root-End Materials: A Question of Choice
}

\author{
Aida Džanković ${ }^{1}$, Naida Hadžiabdić ${ }^{2}$ Samra Korać ${ }^{1}$, Irmina Tahmiščija ${ }^{1}$, Alma Konjhodžić ${ }^{1}$, Lajla Hasić- \\ Branković ${ }^{1}$ \\ ${ }^{1}$ Department of Restorative Dentistry with Endodontics, Faculty of Dentistry with Clinics, University of Sarajevo, Bosnia and \\ Herzegovina, ${ }^{2}$ Department of Oral Surgery, Faculty of Dentistry with Clinics, University of Sarajevo, Bosnia and Herzegovina \\ Correspondence: aidadzankovic@gmail.com; Tel.: + 38733214 249; Fax.: + 38733443395
}

Received: 26 October 2020; Accepted: 19 December 2020

\begin{abstract}
Objectives. The goal of this study was to determine the sealing ability of MTA, Biodentine, and Fuji IX as root-end materials after ultrasonic retrograde preparation using a dye penetration method. Materials and Methods. Seventy permanent anterior teeth were used in this study. Root canals were prepared using rotary endodontic files, and obturated using the lateral condensation technique. The resection of the root apices was performed perpendicularly to the long axis, and $3 \mathrm{~mm}$ deep retrocavities were made by ultrasonic tips. The samples were randomly divided into three experimental groups $(\mathrm{N}=20)$ and two control groups $(\mathrm{N}=5)$. The root-end cavities were filled with mineral-trioxide aggregate (Rootdent MTA, TehnoDent, Russia) in Group 1, Biodentine (Septodont, Saint Maur des Fossés, France) in Group 2 and Fuji IX GP (GC Corporation, Tokyo, Japan) in Group 3. The retrocavities of the positive control group were left unfilled, while retrocavities in the negative control group were sealed using a flowable composite material. The samples were made transparent, and dye penetration was assessed under a stereomicroscope (x10). The data were analyzed with the Kruskal-Wallis test and the Mann-Whitney U-test. Results. The Biodentine group had a lower mean leakage value than the MTA and Fuji IX groups, and the difference was statistically significant $(\mathrm{P}<0.01)$. No statistical difference in apical microleakage was found between the MTA and Fuji IX groups (P>0.05). Conclusion. Within the limitations of this study, it was concluded that Biodentine provides better sealing ability as a root-end material than MTA and Fuji IX. There was no statistically significant difference between the sealing ability of MTA and Fuji IX as root-end materials.
\end{abstract}

Key Words: Sealing Ability • Root-End Material • MTA, Biodentine • Fuji IX.

\section{Introduction}

Elimination of inflamed and necrotic pulp tissue, and cleaning and shaping root canals with proper obturation are the main purposes of conventional endodontic treatment. Conventional root canal treatment is the first therapeutic choice, since this approach results in a high success rate of up to $86-98 \%$ (1). In the case of initial treatment failure, retreatment is inidicated. Endodontic surgery becomes the next therapeutic option to save the tooth's biological function (2) only if non-surgical retreatment is impossible or would not achieve a better result (3). Surgical endodontic treatment involves resectioning the root apex, preparation of the root-end cavity, and forming an apical plug with adequate root-end filling materials.

The choice of the proper material for the retrograde cavity is still an open question in endodontic surgery. The sealing ability of root-end materials is the ability to make intimate contact with the surrounding tissue (4). Microleakage is the constant passage of irritants from the root canal into periapical tissue (and vice versa) through gaps and cracks in the material, or attachment with the surrounding tissues (5). According to Tang et al. (6) sealing ability is a key characteristic of root-end materials that determines the success of periapical surgery. 
Mineral Trioxide Aggregate (MTA) has become the gold standard material (7) for retrograde obturation due to its desirable sealing ability, biocompatibility, and potential to stimulate apical tissue regeneration (8). Biodentine (Septodont, Saint Maur des Fossés, France) is a modified formulation of tricalcium silicate cement with similar desirable characteristics as MTA and simplified application (9). The glass ionomer cement Fuji IX (GC Corporation, Tokyo, Japan) has been used as a restorative material because of its ability to form a chemical bond with hard dental tissues, biocompatibility, and antibacterial effects (10). As already mentioned, Fuji IX is restorative material and the manufacturer does not suggest its application as root-end material in the instructions for use. However, findings from previous studies $(3,4,11)$, as well as the desirable properties of Fuji IX, initiated interest in evaluating its application in endodontic surgery.

The retrograde cavity preparation technique significantly affects the sealing ability of root-end materials (12). The introduction of ultrasonically driven micro tips to apical surgery improved accessibility to the resected apical part of the root, and enables the preparation of a small, deep, and centrally placed retrocavity (12). This retrograde cavity design favors the marginal adaptation of the rootend filling materials and prevents leakage (13).

This in vitro study aimed to determine the sealing ability of MTA, Biodentine, and Fuji IX as root-end materials after ultrasonic retrograde preparation, using a dye penetration method. We hypothesized that there would be no statistical differences in sealing ability between these three root-end materials.

\section{Materials and Methods}

\section{Sample Selection}

Seventy extracted single-rooted teeth (maxillary/ mandibular incisors and canine), with a fully developed apex, were selected for this study. The teeth were collected from patients of the Department of Oral Surgery, Faculty of Dental Medicine in Sarajevo. Previously endodontically treated teeth, teeth with incomplete root development, and teeth with obvious fractures, multiple and obliterated canals and root resorption were excluded from the study.

\section{Sample Preparation}

After extraction, the samples were immersed in $3 \%$ sodium hypochlorite for disinfection and stored until the beginning of the experiment. All debris and deposits were scraped from the sample surface, the samples were sectioned at the gingival part of the root, and the root length was standardized to $18 \mathrm{~mm}$. The three phases of the experimental part were: 1) Root canal instrumentation with obturation; 2) Ultrasonic retropreparation, the application of root-end materials with sample grouping; 3) Clearing technique procedure.

\section{Root Canal Instrumentation with Obturation}

Reamer \#15 (VDW GmbH, Munich, Germany) was introduced into the canal for patency determination. The working length was estimated by reamer \#15, subtracting one $\mathrm{mm}$ from the major apical foramen. According to the manufacturers' instructions, the root canals were instrumented using $\mathrm{Mtwo}^{\oplus}$ rotary endodontic files (VDW GmbH, $\mathrm{Mu}-$ nich, Germany) with $1.5 \%$ sodium hypochlorite irrigation and EDTA lubrication (FileCare ${ }^{\circledast}$ EDTA, VDW GmbH, Munich, Germany). The apical parts of the samples were uniformly enlarged (ISO \#40/.04) at $1 \mathrm{~mm}$ from the tooth apex. Gutta-percha cones (ISO \#40/.04) were coated with AH Plus sealer (Dentsply De Trey GmbH, Germany), fitted to the working length, and the root canals were obturated using the lateral condensation technique. Subsequently, composite resin material (Herculite $\mathrm{XRV}$, Kerr, Germany) was used to seal the coronal surface of the root canals. The samples were stored in saline for one week at room temperature until the sealer setting time had passed.

\section{Ultrasonic Retropreparation and the Application of Root-End Materials}

The apical part of the specimens was resected perpendicular to the longitudinal axis of the tooth, taking care that the resected part was not longer 
than $3 \mathrm{~mm}$. Retropreparation was performed using an NSK Variosurg (Ultrasonic Bone Surgery System) with an ultrasonic microtip (MODEL: E32D-S for anterior teeth $\left./ 90^{\circ}\right)$. The depth of intracanal preparation was also $3 \mathrm{~mm}$. A small 0.9 $\mathrm{mm}$ diameter round filling condenser was used to check the width of the retropreparation.

\section{Sample Grouping}

The samples $(\mathrm{N}=70)$ were randomly divided into 3 experimental groups, and two control groups (positive and negative). Twenty samples were used in each experimental group, while the positive and negative groups consisted of 5 samples each.

Retrograde Cavities in Group 1 were filled with Rootdent MTA (TehnoDent, Belgorod region, Russia). The root-end material was mixed according to the manufacturer's instructions ( 1 dose- 0.25 $\mathrm{g}$ of powder with two drops of distilled water), and a paste suitable for manipulation was obtained after 30 to 40 seconds of mixing. The paste was applied into the retrograde cavities with a plastic instrument, and compacted with a ball-ended burnisher (diameter of $0.9 \mathrm{~mm}$ ). A wet cotton ball was applied to the retrocavity surface to provide a moist environment for the material to set sufficiently.

The Retrograde Cavities in Group 2 were filled with Biodentine (Septodont, Saint Maur des Fossés, France). The material was mixed according to the manufacturer's instructions: 5 drops of liquid from a single-dose container were added to the powder capsule and mixed mechanically for 30 $\mathrm{s}$ at $4500 \mathrm{rpm}$ using an amalgamator. The material was inserted into the retrocavities using a plastic instrument and compacted with a ball-ended burnisher ( $0.9 \mathrm{~mm}$ diameter).

The Retrograde Cavities in Group 3 were filled with GC Fuji IX (GC Corporation, Tokyo, Japan). The material was mixed according to the manufacturer's instructions: 1 scoop of powder and 1 drop of liquid were mixed until a creamy paste was obtained. Twenty retrograde cavities were filled with this paste using a plastic instrument and a $0.9 \mathrm{~mm}$ diameter ball-ended burnisher.
Positive and Negative Control Groups The retrocavities of the positive control group were left unfilled. After adhesive procedures were completed, the retrocavities of the negative control group were sealed using a flowable composite material (Tetric EvoFlow, Ivoclar Vivadent).

\section{Clearing Technique Procedure}

The external surface of the samples in the experimental groups and the positive control group were coated with two layers of nail varnish, except apical $3 \mathrm{~mm}$. The samples of the negative control group were wholly isolated, with two layers of nail varnish. After one week of immersion in Indian ink, the nail varnish was scraped from the sample's surfaces. To achieve demineralization, the samples were stored in $5 \%$ nitric acid solution for 5 days at room temperature, with daily changes of acid. Increasing concentrations of ethyl alcohol (70\%, $95 \%, 99 \%)$ were used for a period of 12 hours to achieve dehydration. The dehydrated samples were placed in methyl salicylate for a period of 24 $h$ to enhance translucency.

\section{Evaluation of Apical Microleakage}

The specimens in the experimental groups were analyzed under a stereomicroscope (Novex RZ-series, Euromex microscopes BV, Netherlands) at x10 magnification. Measurement of apical dye leakage was performed with calipers on images captured by a digital camera (Euromex 5.0 Mpx CCD digital camera). The extend of linear dye penetration measured in millimeters was assessed from the root apex to the most prominent coronal point of dye penetration (Figure 1). One sample from each experimental Group 2 (Biodentine) and Group 3 (Fuji IX) was excluded from further analyzes due to extensive leakage and complete dye penetration along the interface of the root canal filling and the root canal walls. In subsequent evaluations, these two experimental groups (Biodentine and Fuji IX) included 19 samples each. 


\section{Ethics Statement}

The Ethics Committee at the Faculty of Dentistry with Clinics in Sarajevo approved this research (Approval letter No: 02-3-4-189-10/2014).

\section{Statistical Analysis}

Data were analyzed using the SPSS (Statistical Package for the Social Sciences) version 23. Preliminary analyses were conducted to specify the distribution of the dependent variables. Apical leakage data showed non-parametric distribution. In further analysis, the Kruskal-Wallis test and the MannWhitney U-test were used to determine the statistical differences in microleakage between the three experimental groups, at a significance level of $5 \%$.

\section{Results}

All the samples in the positive control group showed maximum values of apical microleakage, but no apical leakage was observed in the negative control group (Figure 1).

The descriptive values of apical microleakage are shown in Table 1 . The positive asymmetry of the distributions was confirmed statistically: the values of Skewness and Kurtosis exceeded the values of the corresponding standard errors more than 3 times in each distribution (Table 1). The highest median value of microleakage was determined in the MTA group ( $\mathrm{Mdn}=0.39 \mathrm{~mm}$; value range: $0-2.60 \mathrm{~mm}$ ), while median values in the Biodentine and Fuji IX groups were zero (Table 1). The Kruskal-Wallis test revealed a statistically

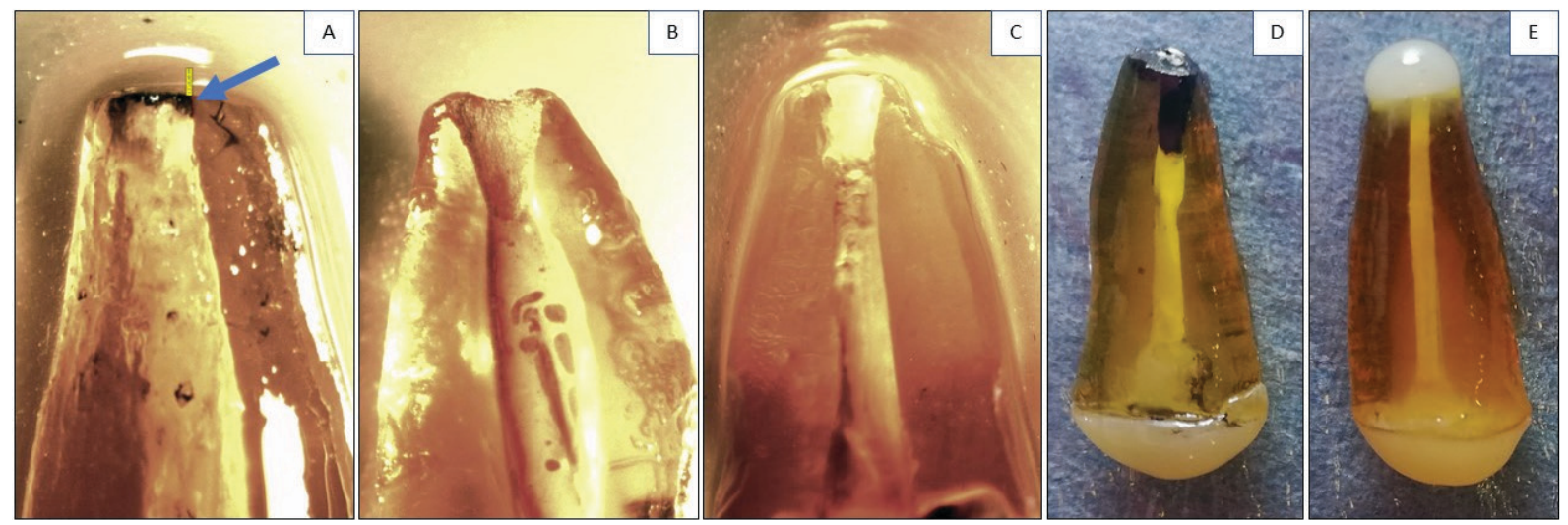

Figure 1. (A) The sample of the MTA group. The arrow shows apical dye leakage on the interface of the root-end materials and the walls of the retrograde cavity. (B) The samples of the Biodentine group and (C) the Fuji IX group, show a complete apical plug where no apical leakage was found. (D) The positive control group revealed maximum leakage, while the negative control group (E) was completely clear, without the evidence of dye penetration.

Table 1. Descriptive Values of Apical Microleakage $(\mathrm{mm})$ for Three Different Types of Root-End Material

\begin{tabular}{|c|c|c|c|c|c|c|c|c|c|c|}
\hline \multirow{2}{*}{ Root-end material } & \multirow{2}{*}{$\mathrm{N}$} & \multirow{2}{*}{ M } & \multirow{2}{*}{ sd } & \multirow{2}{*}{ Min } & \multirow{2}{*}{ Q1 } & \multirow{2}{*}{ Med } & \multirow{2}{*}{ Q3 } & \multirow{2}{*}{ Max } & Skewness & Kurtosis \\
\hline & & & & & & & & & (SE) & (SE) \\
\hline \multirow{2}{*}{ MTA } & \multirow{2}{*}{20} & \multirow{2}{*}{0.55} & \multirow{2}{*}{0.64} & \multirow{2}{*}{0.00} & \multirow{2}{*}{0.06} & \multirow{2}{*}{0.39} & \multirow{2}{*}{0.70} & \multirow{2}{*}{2.60} & 2.11 & 5.15 \\
\hline & & & & & & & & & $(0.51)$ & $(0.99)$ \\
\hline \multirow{2}{*}{ Biodentin } & \multirow{2}{*}{19} & \multirow{2}{*}{0.08} & \multirow{2}{*}{0.33} & \multirow{2}{*}{0.00} & \multirow{2}{*}{0.00} & \multirow{2}{*}{0.00} & \multirow{2}{*}{0.00} & \multirow{2}{*}{1.46} & 4.36 & 19.00 \\
\hline & & & & & & & & & $(0.52)$ & $(1.01)$ \\
\hline \multirow{2}{*}{ Fuji IX } & \multirow{2}{*}{19} & \multirow{2}{*}{0.41} & \multirow{2}{*}{0.67} & \multirow{2}{*}{0.00} & \multirow{2}{*}{0.00} & \multirow{2}{*}{0.00} & \multirow{2}{*}{0.68} & \multirow{2}{*}{2.34} & 2.03 & 3.83 \\
\hline & & & & & & & & & $(0.52)$ & $(1.01)$ \\
\hline
\end{tabular}

$\mathrm{MTA}=$ Mineral trioxide aggregate; $\mathrm{N}=$ Sample size; $\mathrm{M}=$ Arithmetic mean; $\mathrm{SD}=$ Standard deviation; Min=Minimal value in distribution; $\mathrm{Q} 1=$ First quartile, i.e. 25th percentile of the data; Med=Median, i.e. 50th percentile of the data; Q3=Third quartile, i.e. 75th percentile of the data; Max=Maximal value in distribution; $\mathrm{SE}=$ Standard error. 
Table 2. Mann-Whitney Test Statistics for Differences in Apical Microleakage Values $(\mathrm{mm})$ between Different Types of Root-Ending Material

\begin{tabular}{|c|c|c|c|c|c|}
\hline $\begin{array}{l}\text { Root-end } \\
\text { material }\end{array}$ & $\begin{array}{l}\text { Mean } \\
\text { range }\end{array}$ & $\begin{array}{l}\text { Mann-Whitney } \\
\text { U }\end{array}$ & Z & $P$ & $r$ \\
\hline MTA & 26.35 & \multirow{2}{*}{63.00} & \multirow{2}{*}{-4.00} & \multirow{2}{*}{0.0001} & \multirow{2}{*}{-0.89} \\
\hline Biodentine & 13.32 & & & & \\
\hline MTA & 22.08 & \multirow{2}{*}{148.50} & \multirow{2}{*}{-1.21} & \multirow{2}{*}{0.2269} & \multirow{2}{*}{-0.27} \\
\hline Fuji IX & 17.82 & & & & \\
\hline Biodentine & 16.11 & \multirow{2}{*}{116.00} & \multirow{2}{*}{-2.53} & \multirow{2}{*}{0.0115} & \multirow{2}{*}{-0.58} \\
\hline Fuji IX & 22.89 & & & & \\
\hline
\end{tabular}

MTA $=$ Mineral trioxide aggregate.

significant difference in microleakage between the experimental groups $\mathrm{X}^{2}(2)=14.83, \mathrm{P}<0.01$. Additional post hoc analysis (Table 2 ) showed statistically significant differences in microleakage between Biodentine and MTA (Mann-Whitney $\mathrm{U}=63.00, \mathrm{Z}=-4.00, \mathrm{P}<0.01, \mathrm{r}=-0.89)$ and Biodentine and Fuji IX (Mann-Whitney $U=116.00, Z=-$ 2.53, $\mathrm{P}=0.01, \mathrm{r}=-0.58)$. No statistically significant difference in microleakage was found between MTA and Fuji IX (Mann-Whitney=148.50, Z=1.21, $\mathrm{P}>0.05, \mathrm{r}=-0.27)$.

\section{Discussion}

The results of apical microleakage are affected by several factors. Besides the properties of root-end materials and their sealing ability, the methodology of assessment, root canal morphology and the diameter of the root canal may have an influence on the sealing ability results.

Various methods of microleakage evaluation have been used, such as dye penetration, fluid filtration method, bacterial leakage, radioactive isotopes, scanning electron microscopy and others. It is important to emphasize that no standard method of microleakage assessments exists, and there is a lack of technical standardization even when the same methodology is used (14-16). The lack of standardization is probably the main reason why there are so many different methods to study the same phenomenon.

Dye penetration methods are commonly used in the detection of apical leakage. In our research, the clearing technique was used, primarily due to the possibility of three-dimensional observation of the apical microleakage. It is a simple, inexpensive procedure, on a biological substrate that is not destroyed by the evaluation method itself (14). The application of the clearing techique is based on the possibility of a dye to penetrate voids and cracks formed on the interface between the material and dental tissue. At the end of the clearing procedure, the tooth becomes completely transparent, allowing the precise measurement of the dye penetration inside the root canal in tenths of millimeters (17). The high-resolution images can be acquired and the specimen can be preserved for a long time at different study periods.

Also, the clearing technique has the limitations. When the clearing procedure is not performed correctly (e.g. reduction of demineralization period), the samples are opaque and dye penetration readings are not possible. The entrapped air could block the dye penetration, and applications of different types of dye may change the result (18). This method has been criticized because of its limited clinical relevance, but it is also a proven and efficient method to diagnose and visualize cracks and voids inside root canals (11).

Complete debridement of the root canals with complex root canal morphology is difficult to obtain, and most previous studies have comprised the evaluation of sealing ability on single root canals (19). Maxillary incisors and canines were selected as they have a simple root canal morphology. CBCT evaluations of root canal morphology revealed that $97-100 \%$ of maxillary incisors and canines have one root and one canal (20). Compared to maxillary incisors, mandibular incisors have one root (99.92-100\%), and more frequently two canals (14.4-20.2\%) (20). The mandibular canine has one root ( $98.57 \%$ of samples) and one canal (92.4\% of samples) (20).

More interesting is research related to the diameter of the root canal. Wu et al. (21) analyzed root canal diameters at a different distance from the apex, and found that the occurrence of the long oval canal was $>50 \%$ in some tooth groups at $5 \mathrm{~mm}$ from the apex. In particular the mandibular 
incisors are considerably broader buccolingually than mesiodistally (20), and oval-shaped canals in the apical third were not uncommon $(22,23)$. NiTi rotary files are less effective in the instrumentation of oval-shaped canals (24) and some root canal surfaces may remain untreated. These are favorable conditions for the accumulation of debris and microorganisms (25), are difficult to clean and shape, and become obturated. Extensive leakage was seen in two samples from the Biodentine and Fuji IX groups. This result might be attributed to the inability of the lateral condensation technique to fill the untreated surfaces of the samples with oval-shaped root canals.

Apical microleakage was observed in all the experimental groups, however the results of this study show the advantage of Biodentine over MTA and Fuji IX in terms of their sealing ability. The results of this study are in agreement with previous studies (26-29). Khandelwal et al. compared the effects of ultrasonic and conventional techniques of retropreparation on the sealing ability of Biodentine and MTA under a confocal laser scanning microscope (26). Biodentine and ultrasonic preparation showed significantly less microleakage than MTA. Naik at al. evaluated the apical seal of mineral trioxide aggregate (MTA) and Biodentine as root-end materials after irrigation with MTAD (a mixture of doxycycline, citric acid and a detergent). Compared to MTA, the apical seal obtained with Biodentine was superior (27). Chakmakchi et al. evaluated the sealing ability of Biodentine, MTA and glass iomomer cement (GIC) using a dye penetration model on longitudinal sections. The results of their study indicated that Biodentine provides a better seal as a retro filling material than MTA and GIC. In agreement with our results, no statistically significant difference in sealing ability was found between MTA and GIC (28). Pathak et al. analyzed the sealing ability of MTA, Biodentine, GIC and IRM using a scanning electron microscope and a stereomicroscope on longitudinal sections (29). It was concluded that Biodentine exhibited better sealing ability compared to MTA, GIC and IRM. In that study, no statistically significant difference between the materials was found, probably because of the smaller sample size than in the present study.

The better sealing ability of Biodentine may be related to its smaller particle size and low porosity. According to Camilleri et al., Biodentine exhibited a low average pore diameter in a range of 0.01-0.05 $\mu \mathrm{m}$, and low porosity (30). During hydration reactions, the hydration products fill the gaps between the un-hydrated cement grains (30). These physical properties contribute to better marginal adaptation to the cavity walls and decrease the chances of leakage. The small pore volume of the material allows better penetration into the dentine tubules. The lower sealing ability of MTA may be attributed to its greater particle size (27). This is supported by the findings of Ravichandra et al., who reported that Biodentine showed better marginal adaptation as root-end material than MTA and Glass ionomer cement (31).

In our study, the pre-dose capsulate formulation of Biodentine was used. Consequently, variations in water/powder ratio were reduced to a minimum, and a homogeneous consistency was obtained by mixing the material in an amalgamator. However, MTA was mixed manually and, according to the manufacturer's instructions, it was permitted to add more liquid to obtain paste consistency. In this way, the liquid/powder ratio varies in each preparation. Excess water leads to void formation, increases the porosity of the root-end material (30), and affects the sealing ability results. The results of this study may be attributed to the formation of tag-like structures at the materialdentin interface. Biodentine and MTA generated uptake of calcium and silicate ions in the adjacent root canal dentine in the presence of phosphate-buffered saline (32). Formation of tag-like structures alongside an interfacial layer was more prominent in Biodentine than MTA $(32,33)$. This crystal formation has the potential to increase the sealing ability of Biodentine (34), because apatite crystals fill the gaps along with the interface of the tricalcium silicate cement and root dentin.

Dimensional changes in root-end materials in different environments may affect apical microleakage. In dry conditions, MTA did not show any 
dimensional changes, while Biodentine demonstrated shrinkage and crack formation. In wet conditions, Biodentine and MTA showed expansion, but in blood, both materials presented shrinkage through time. Dimensional changes of root-end materials disrupt marginal adaptation and lead to microleakage (35).

At the end of the clearing procedure, it was evident that some root-end materials were lost and missing from the retrograde cavity. Washout is the tendency of freshly prepared cement paste to disintegrate in contact with blood or other fluids. It has been reported that Biodentine has a very high washout tendency (36) and solubility (37). The clearing technique used in this study implies the application of different solutions for several days. This may explain the most frequent loss of retrograde filling from the Biodentine group in our study.

\section{Limitations of the Study}

The limitation of the present study was the evaluation of apical microleakage in in vitro conditions for a relatively short period. Nabeel et al. (2019) showed a difference in the leakage values at different time intervals between MTA and Biodentine (38).

\section{Conclusion}

Within the limitation of this study, it was concluded that Biodentine provides better sealing ability as a root-end material, than MTA and Fuji IX. There were no statistically significant differences between the sealing ability of MTA and Fuji IX as root-end materials.

\section{What Is Already Known on this Topic:}

The success of endodontic surgery is closely related to the selection of appropriate root-end filling materials. These materials should hermetically seal the retrograde cavity and prevent the passage of microorganisms and/or their toxins through the apical foramen into the periapical tissues, and vice versa. Currently, no root-end filling material has achieved a fluid-tight seal. Therefore, the search for the root-end material of good sealing ability continues.

What this Study Adds:

Evaluation of the sealing ability of MTA, Biodentine and Fuji IX as root-end materials by the clearing technique was not found in any previous study. The results of this study contribute to knowledge about optimal root-end material in daily practice.
Acknowledgments. The authors would like to thank Ratko Đokić, Assistant Professor (The Department of Psychology, Faculty of Philosophy of the University of Sarajevo) for help in statistical analysis and interpretation of data.

Authors' Contributions: Conception and design: ADž and NK; Acquisition, analysis and interpretation of data: SK, IT, $\mathrm{NH}$ and ADž; Drafting the article: ADž, NK, SK and IT; Revising it critically for important intellectual content: ADž, NK, SK, IT, AK and LHB; Approved final version of the manuscript: ADž, NK, SK, IT, AK and LHB.

Conflict of Interests: The authors declare that they have no conflict of interests.

\section{Reference}

1. Tabassum S, Khan FR. Failure of endodontic treatment: The usual suspects. Eur J Dent. 2016;10(1):144-7.

2. von Arx T. Apical surgery: A review of current techniques and outcome. Saudi Dent J. 2011;23(1):9-15.

3. Siqueira JF Jr, Rôças IN, Abad EC, Castro AJ, Gahyva SM, Favieri A. Ability of three root-end filling materials to prevent bacterial leakage. J Endod. 2001;27(11):673-5.

4. De Bruyne MA, De Moor RJ. SEM analysis of the integrity of resected root apices of cadaver and extracted teeth after ultrasonic root-end preparation at different intensities. Int Endod J. 2005;38(5):310-9.

5. Muliyar S, Shameem KA, Thankachan RP, Francis PG, Jayapalan CS, Hafiz KA. Microleakage in endodontics. J Int Oral Health. 2014;6(6):99-104.

6. Tang JJ, Shen ZS, Qin W, Lin Z. A comparison of the sealing abilities between Biodentine and MTA as rootend filling materials and their effects on bone healing in dogs after periradicular surgery. J Appl Oral Sci. 2019;27:e20180693.

7. Solanki NP, Venkappa KK, Shah NC. Biocompatibility and sealing ability of mineral trioxide aggregate and biodentine as root-end filling material: A systematic review. J Conserv Dent. 2018;21(1):10-5.

8. Tawil PZ, Duggan DJ, Galicia JC. Mineral trioxide aggregate (MTA): its history, composition, and clinical applications. Compend Contin Educ Dent. 2015;36(4):247-52.

9. Kaur M, Singh H, Dhillon JS, Batra M, Saini M. MTA versus Biodentine: Review of Literature with a Comparative Analysis. J Clin Diagn Res. 2017;11(8):ZG01-5.

10. Sidhu SK, Nicholson JW. A Review of Glass-Ionomer Cements for Clinical Dentistry. J Funct Biomater. 2016;7(3):16.

11. De Bruyne MA, De Moor RJ. Influence of cracks on leakage and obturation efficiency of root-end filling materials after ultrasonic preparation: an in vitro evaluation. Quintessence Int. 2008;39(8):685-92. 
12. Premjith, Shetty D, Kailar A, Pare S, Kumar P, Ragher M. The effect of root end cavity preparation using Er,Cr:YSGG laser, ultrasonic retrotip, and bur on the apical microleakage of retrograde cavity filled with MTA Plus. J Pharm Bioall Sci. 2020;12(Suppl 1):299-303.

13. Kadić S, Baraba A, Miletić I, Ionescu A, Brambilla E, Ivanišević Malčić A, et al. Push-out bond strength of three different calcium silicate-based root-end filling materials after ultrasonic retrograde cavity preparation. Clin Oral Investig. 2018;22(3):1559-65.

14. Jafari F, Jafari S. Importance and methodologies of endodontic microleakage studies: A systematic review. J Clin Exp Dent. 2017;1;9(6):e812-9.

15. Celikten B, Uzuntas CF, Orhan AI, Tufenkci P, Misirli M, Demiralp KO, et al. Micro-CT assessment of the sealing ability of three root canal filling techniques. J Oral Sci. 2015;57(4):361-6.

16. Veríssimo DM, do Vale MS. Methodologies for assessment of apical and coronal leakage of endodontic filling materials: a critical review. J Oral Sci. 2006;48(3):93-8.

17. Reddy A, Garg G, Janardhanan S, Uthappa R, Arora S, Singh NK. An In Vitro Evaluation of Apical Leakage in Gutta-percha/ AH Plus and Resilon/Epiphany-filled Root Canals Using Two Dye Penetration Techniques. J Contemp Dent Pract. 2019;1;20(2):152-7.

18. Schäfer E, Olthoff G. Effect of three different sealers on the sealing ability of both thermafil obturators and cold laterally compacted Gutta-Percha. J Endod. 2002;28(9):638-42.

19. Long W, Li J, Liu Y, Jiang H. Effect of obturation technique with immediate and delayed post space preparation on apical voids and bond strength of apical gutta-percha. J Int Med Res. 2019;47(1):470-80.

20. Versiani MA, Basrani B, Sousa-Neto MD, editors. The Root Canal Anatomy in Permanent Dentition. 1st ed. Cham: Springer International Publishing; 2019.

21. Wu MK, R’oris A, Barkis D, Wesselink PR. Prevalence and extent of long oval canals in the apical third. Oral Surg Oral Med Oral Pathol Oral Radiol Endod. 2000;89(6):73943.

22. Almeida MM, Bernardineli N, Ordinola-Zapata R, VillasBoas MH, Amoroso-Silva PA, Brandão CG, et al. Microcomputed tomography analysis of the root canal anatomy and prevalence of oval canals in mandibular incisors. J Endod. 2013;39(12):1529-33.

23. Shemesh A, Kavalerchik E, Levin A, Ben Itzhak J, Levinson O, Lvovsky A, et al. Root Canal Morphology Evaluation of Central and Lateral Mandibular Incisors Using Cone-beam Computed Tomography in an Israeli Population. J Endod. 2018;44(1):51-5.

24. Helvacioglu-Yigit D, Orucoglu H, Yavuz T, Yavuz CI, Yilmaz A, Kaba YN, et al. An evaluation of the apical seal in oval-shaped root canals prepared with either self- adjusting files or protaper files. Cumhuriyet Dent J. 2014;17(2):109-16.
25. Espir CG, Nascimento-Mendes CA, Guerreiro-Tanomaru JM, Cavenago BC, Hungaro Duarte MA, Tanomaru-Filho M. Shaping ability of rotary or reciprocating systems for oval root canal preparation: a micro-computed tomography study. Clin Oral Investig. 2018;22(9):3189-94.

26. Khandelwal A, Karthik J, Nadig RR, Jain A. Sealing ability of mineral trioxide aggregate and Biodentine as root end filling material, using two different retro preparation techniques-An in vitro study. Int J Contemp Dent Med Rev. 2015;2015:150115.

27. Naik MM, de Ataide Ide N, Fernandes M, Lambor R. Assessment of apical seal obtained after irrigation of root end cavity with MTAD followed by subsequent retrofilling with MTA and Biodentine: An in vitro study. J Conserv Dent. 2015;18(2):132-5.

28. Chakmakchi MN, Yahya MM, AL-Ashou WM. Sealing Ability of Biodentine as a Retrograde Filling Materials (A Comparative in vitro study). Al-Rafidain Dent J. 2013;14(3):357-61.

29. Pathak S. Comparative Evaluation of Sealing Ability of Root End Filling Materials: An In-Vitro Study. Int J Dent Med Res. 2015;1(5):48-52.

30. Camilleri J, Grech L, Galea K, Keir D, Fenech M, Formosa $\mathrm{L}$ et al. Porosity and root dentine to material interface assessment of calcium silicate-based root-end filling materials. Clin Oral Investig. 2014;18(5):1437-46.

31. Ravichandra P V, Vemisetty H, Deepthi K, Reddy JS, Remkiran D, Krishna JNM, et al. Comparative Evaluation of Marginal Adaptation of BiodentineTM and Other Commonly Used Root End Filling Materials-An Invitro Study. J Clin Diagn Res. 2014;8(3):243-5.

32. Han L, Okiji T. Uptake of calcium and silicon released from calcium silicate-based endodontic materials into root canal dentine. Int Endod J. 2011;44(12):1081-7.

33. Atmeh AR, Chong EZ, Richard G, Festy F, Watson TF. Dentin-cement interfacial interaction: calcium silicates and polyalkenoates. J Dent Res. 2012;91(5):454-59.

34. Malkondu Ö, Karapinar Kazandağ M, Kazazoğlu E. A review on biodentine, a contemporary dentine replacement and repair material. Biomed Res Int. 2014;2014:160951.

35. Aksel H, Küçükkaya Eren S, Askerbeyli Õrs S, Karaismailoğlu E. Surface and vertical dimensional changes of mineral trioxide aggregate and biodentine in different environmental conditions. J Appl Oral Sci. 2018;27:e20180093.

36. Grech L, Mallia B, Camilleri J. Investigation of the physical properties of tricalcium silicate cement-based rootend filling materials. Dent Mater. 2013;29(2):e20-8.

37. Singh S, Podar R, Dadu S, Kulkarni G, Purba R. Solubility of a new calcium silicate-based root-end filling material. J Conserv Dent. 2015;18(2):149-53.

38. Nabeel M, Tawfik HM, Abu-Seida AMA, Elgendy AA. Sealing ability of Biodentine versus ProRoot mineral trioxide aggregate as root-end filling materials. Saudi Dent J. 2019;31(1):16-22. 